\title{
ANÁLISE DO USO E OCUPAÇÃO DO SOLO NO ENTORNO DO RIO AZUIS - TOCANTINS
}

\author{
Luiz Ricardo Ferreira Alves ${ }^{(a)}$, Fernando de Morais ${ }^{(b)}$ \\ (a) Mestrando do Programa de Pós-Graduação em Geografia (PPGG), Universidade Federal do Tocantins - Campus \\ Porto Nacional, E-mail: luizricardo_geo@yahoo.com.br \\ (b) Professor Doutor Adjunto do Departamento de Geografia, Universidade Federal do Tocantins - Campus Porto \\ Nacional, E-mail: morais@uft.edu.br
}

Eixo: USO E OCUPAÇÃO DAS TERRAS E LEGISLAÇÃO AMBIENTAL

\begin{abstract}
Resumo
O presente trabalho busca analisar os aspectos relacionados ao uso e ocupação do solo no entorno do rio Azuis, situado no município de Aurora do Tocantins, na região sudeste do estado do Tocantins. A área apresenta grande importância ambiental devido à presença de paisagens cársticas, no entanto as diversas atividades humanas têm aumentado a fragilidade do carste. Foram realizados trabalhos de campo através do método de caminhamento livre para descrição da paisagem com o intuito de observar as possíveis alterações sofridas, e com a utilização de imagens de satélite Landsat 8 foi produzido um mapa de uso e ocupação do solo por meio da classificação supervisionada. Os resultados obtidos mostram que no entorno do rio Azuis, destacam-se como principais atividades a agricultura, pecuária, desmatamento e queimadas. O turismo também se sobressai, trazendo várias consequências no ambiente como: produção de lixo, pavimentação em áreas impróprias, falta de infraestrutura e fiscalização no local.
\end{abstract}

Palavras chave: Rio Azuis, Carste, Uso e ocupação.

\section{Introdução}

Vários impactos nas paisagens são gerados por ações antrópicas, influenciados por intensos processos que substituem as áreas naturais por áreas modificadas, para suprir as necessidades da sociedade, ou pelo menos uma porção desta. A prática da agricultura e pecuária tem interferência considerável no equilíbrio natural, quando a cobertura vegetal é retirada para introdução de pastagens e lavouras, gerando sérias consequências. Se comparados a outros sistemas, nas áreas cársticas essa questão é mais grave por serem paisagens mais frágeis e vulneráveis às interferências humanas.

Para Silva e Morais (2011), nos ambientes cársticos o desmatamento é uma das atividades que mais se destaca por ser praticada para fins urbanísticos, agricultura, pastagem entre outras atividades que contribuem para mudanças consideráveis.

Segundo Travassos e Varela (2008), paisagens cársticas apresentam uma diversidade de formas topográficas ocasionadas, sobretudo pelo intemperismo químico sob controles litológicos, estruturais, 


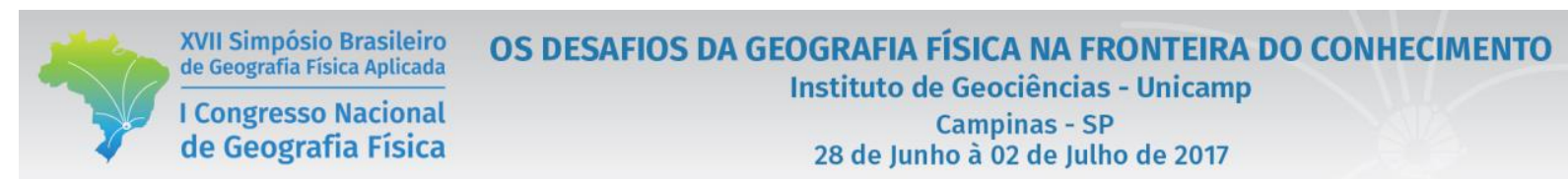

tectônicos e o grau de solubilidade da rocha. Assim, para compreensão do carste, deve-se considerá-lo como um sistema de formas positivas e negativas que se desenvolvem em constante harmonia, sendo facilmente afetada pela ação humana.

Nesse contexto, o presente estudo busca analisar as atividades de uso e ocupação do solo no entorno do rio Azuis por meio de observação de campo, e o quanto estas atividades humanas contribuem na geração de impactos ambientais na paisagem cárstica.

\section{2. Área de estudo}

A área do rio Azuis está situada na porção sudeste do estado do Tocantins, onde se encontra grande parte das rochas carbonáticas, no município de Aurora do Tocantins (Figura 1). De acordo com Morais (2013), além de possuir atributos cênicos que atraem muitos turistas, caracteriza-se como uma surgência cárstica com apenas 137 metros de extensão (entendida pela população regional como o menor rio do Brasil).

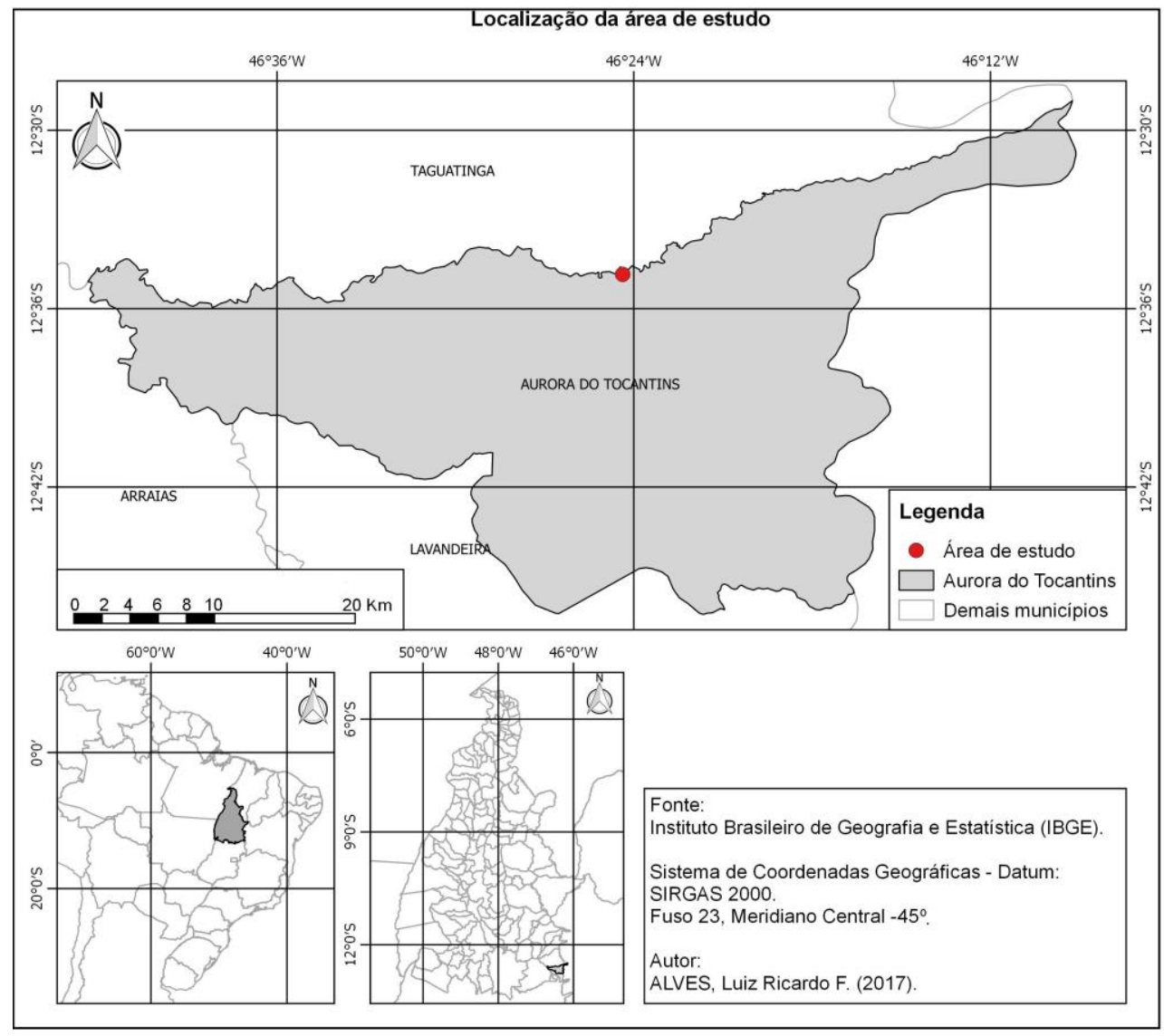

Figura 1 - Localização da área de estudo. 
O clima é subúmido seco com deficiência hídrica moderada no inverno, possui temperatura média anual com variação de 25 a $27^{\circ} \mathrm{C}$ e precipitações médias anuais entre 1400 e 1600 mm (SEPLAN, 2008).

De acordo Morais (2012), a área encontra-se geologicamente inserida nos domínios da Bacia Sedimentar Sanfranciscana, com ocorrência das unidades geológicas do Complexo Almas-Cavalcante (Embasamento Cristalino), Grupo Bambuí, Grupo Urucuia, Grupo Areado e Depósitos Aluvionares Recentes.

O Grupo Urucuia destaca-se mais visivelmente na porção leste da área cárstica de Aurora do Tocantins, porém pode ser visto também em outros locais da região. Data do Cretáceo e apresenta afloramentos que compõem a Serra Geral. É composto pelas formações Posse e Araras, constituído de arenitos com níveis de pelito, arenitos conglomeráticos e ocorrência de conglomerados (CAMPOS; DARDENE, 1977).

O Grupo Bambuí possui o maior conjunto de ocorrências calcárias favoráveis à presença de cavernas no Brasil, em decorrência a sua vasta distribuição (KARMANN; SANCHEZ, 1979). De acordo com Iglesias e Uhlein (2009), sua constituição provém da Era Neoproterozóica, que possui ampla distribuição no Cráton do São Francisco. Possui litofáceis siliciclásticas e bioquímicas associadas, como sedimentos em plataforma, aplicado em mar epicontinental de grande extensão. É composto por calcarenitos, dolomitos, ritimitos, margas, argilitos, siltitos, arcoses e calcários, compondo o Subgrupo Paraopeba.

No que diz respeito a geomorfologia, é dominada por um pediplano degradado inumado constituindo a Serra Geral, compondo o Planalto Divisor das Bacias Hidrográficas dos rios São Francisco e Tocantins (MORAIS, 2012). Superfícies de aplainamento podem ser observadas nos topos do Chapadão Central, onde por meio de sedimentos da Bacia Sanfranciscana, houve a formação de sua estrutura. Topos planos com interflúvios largos com baixo grau de dissecação causados por ravinamentos integram o nível do Chapadão (BRASIL, 1982).

O remanejamento constante de areia é percebido nas áreas de maior elevação para as áreas mais deprimidas, onde se encontram as veredas. Isso ocorre em regiões de relevos tabuliformes e cuesteformes, em que os processos geomorfológicos são os mesmos responsáveis pela evolução da paisagem (BRASIL, 1982).

No tocante à vegetação, a mesma apresenta predomínio típico do bioma cerrado com diferentes composições denominadas de Campo Limpo, Campo Sujo, Cerradão com partes compostas por formações florestais de veredas, várzeas, campos rupestres entre outros (INVTUR, 2008).

\section{Materiais e metodologia}


A metodologia do estudo constitui em trabalho de campo, porém para um conhecimento prévio e organização espacial da paisagem, foram realizados planejamentos, levantamento cartográfico e bibliográfico (CAVALCANTI, 2014). Como resultado foi confeccionado o mapa de uso e ocupação do solo para uma melhor orientação e interpretação da paisagem com o objetivo de atualizar as informações da área. A confecção do mapa e a manipulação dos dados foram feitos no software livre QGIS (versão 2.14.1).

Imagens do Google Earth (ano 2016) serviram como base para definição dos locais a serem observados. As bases vetoriais foram disponibilizadas no Instituto Brasileiro de Geografia e Estatística (IBGE), os dados vetoriais de hidrografia do estado do Tocantins foram providenciados na Secretaria de Planejamento do Tocantins (SEPLAN - TO), dados SRTM do Projeto Topodata (VALERIANO, 2005) auxiliaram na análise da elevação da área de estudo com base no Modelo Digital de Elevação (MDE).

Por meio de imagens de satélite Landsat 8 disponíveis gratuitamente no site Earth Explorer, com referência ao mês de novembro de 2016 (órbita 220 ponto 069), foi feita a correção atmosférica para o ajuste da reflectância de superfície, em seguida para uma melhor vizualização, foi feita a composição colorida das bandas 5(R), 4(G) e 3(B). Com a obtação do resultado, foi elaborada a classificação supervisionada e posteriormente o mapa de uso e ocupação do solo.

A técnica de classificação supervisionada para o mapa de uso e ocupação foi executada com o intuito de mensurar os elementos na área de estudo. De acordo com Novo (2010), esse procedimento permite identificar os alvos por meio de amostras de pixels, reconhecendo as características da superfície terrestre. Concluída a classificação supervisionada, edições e correções posteriores foram realizadas para um resultado final satisfatório, e condizente com as observações feitas em campo.

Por ser mais flexível, o método de observação da paisagem utilizado em campo foi o proposto por Cavalcanti (2014), o qual não segue um caminho definido, e novos locais a serem observados podem ser adicionados durante o percurso, dependendo da necessidade e do acesso aos pontos de observação. $\mathrm{O}$ campo foi realizado para análise, coleta de informações e atualização das coordenadas geográficas em dezembro de 2016.

\section{Resultados e Discussão}

A área de estudo apresenta as principais classes de uso da terra: Afloramentos Rochosos, Mata de Galeria, Campo Rupestre e Cerrado Sentido Restrito (Figura 2). O trabalho buscou analisar as alterações sofridas 
XVII Simpósio Brasileiro

de Geografia Física Aplicada

I Congresso Nacional

de Geografia Física
OS DESAFIOS DA GEOGRAFIA FÍSICA NA FRONTEIRA DO CONHECIMENTO

Instituto de Geociências - Unicamp

Campinas - SP

28 de Junho à 02 de Julho de 2017

pelo uso e ocupação da parte superficial do relevo, ou seja no exocarste, onde estão presentes as formas cársticas mais típicas como: os lapiás (karren), dolinas, uvalas, poljés, sumidouros e maciços calcários.

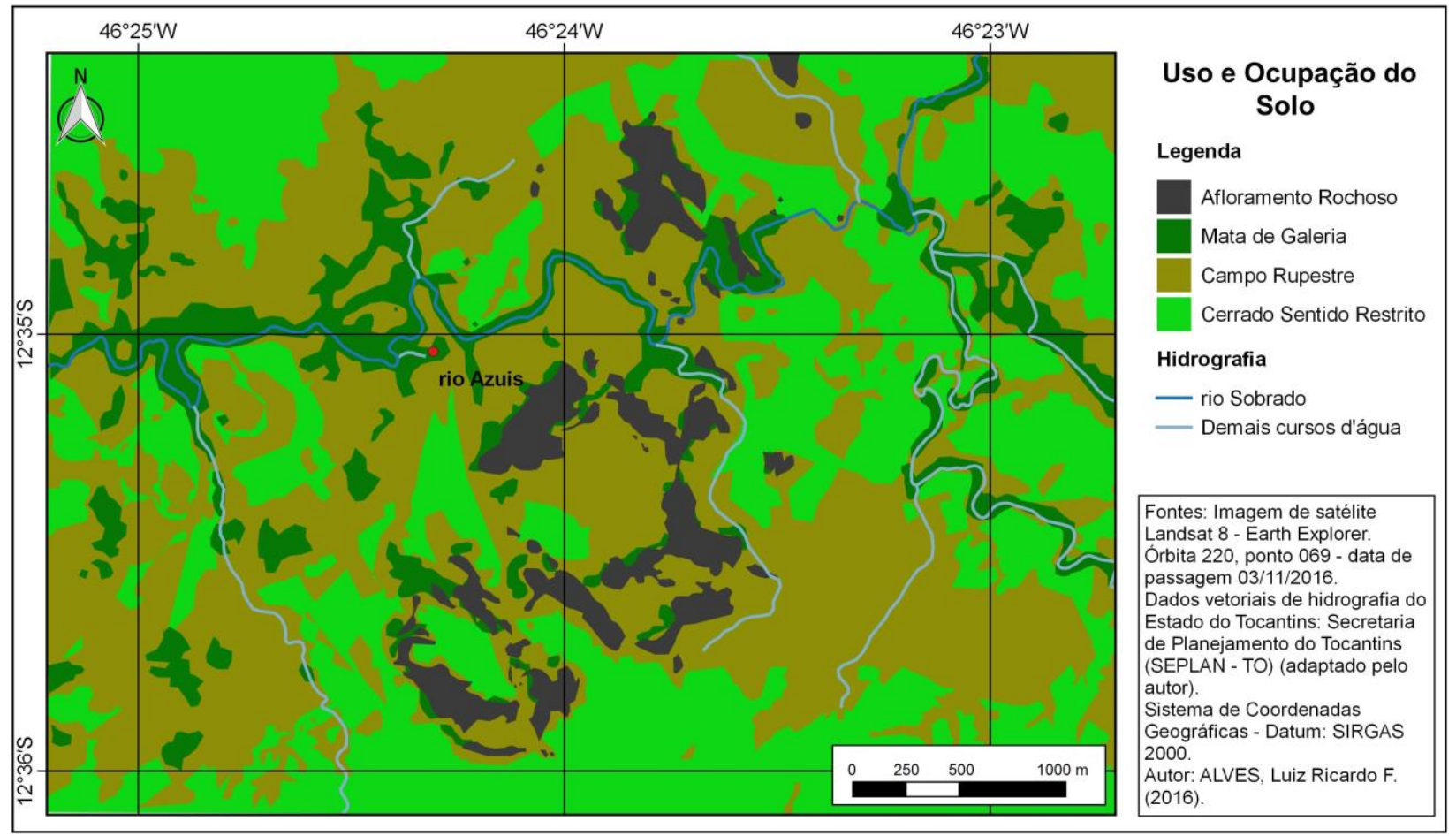

Figura 2 - Principais formas de aproveitamento do solo.

Várias são as atividades que podem afetar os sistemas cársticos, sendo elas diretas ou indiretas. Assim, Williams (1993 apud HARDT, 2008, p.1295) mostra diversos problemas relacionados a essas ações e como seus efeitos resultarão em impactos no carste, como: o desflorestamento, que afeta a vegetação e os solos, reduzindo a evapotranspiração e aumentando os processos erosivos; a agricultura, que gera aumento da erosão e o descarte de lixo na água compromentendo sua qualidade; a urbanização, proporcionando as chuvas ácidas e remoção das rochas e minerais, destruíndo o relevo e comprometendo também a qualidade da água, entre outros. Piló e Auler (2001) destacam o desmatamento como uma das principais atividades que gera pertubações no ambiente.

Ao estudar as paisagens cársticas não se pode levar em consideração apenas os impactos gerados no exocarste, pois qualquer atividade realizada, por menor que seja, sempre trará consequências não apenas na parte superficial (exocarste), mas também na subsuperficial (epicarste) e subterrânea do carste (endocarste), afetando a dinâmica das cavernas. Essa relação, somada as especificidades desses ambientes, os caracterizam por sua fragilidade, sendo suceptíveis aos impactos antrópicos que, dependendo do tipo, se propagam com rapidez não sendo possível realizar seu controle (FERREIRA, 2011). 
XVII Simpósio Brasileiro

de Geografia Fisica Aplicada

I Congresso Nacional

de Geografia Física
OS DESAFIOS DA GEOGRAFIA FÍSICA NA FRONTEIRA DO CONHECIMENTO

Instituto de Geociências - Unicamp

Campinas - SP

28 de Junho à 02 de Julho de 2017

A cobertura vegetal exerce um importante papel no que diz respeito aos processos cársticos e manuntenção dos solos. Sua ausência pode gerar vários problemas como: exposição do solo a ação direta da água das chuvas, a não formação da camada orgânica resultante do depósito das folhas das árvores, além de não produzir o dióxido de carbono decorrente dos processos de decomposição, fundamental aos processos cársticos, devido ao não estabelecimento da fauna e flora no solo (GILLIESON, 1996).

As Matas de Galeria presentes nos rios Sobrado e Azuis, que também são distribuídas em outras localidades da área de estudo, estão expostas aos distúrbios, sendo retiradas para a realização da prática de agricultura de subsistência, principalmente nas planícies de inundação. Foi possível observar a presença de pisoteio de gado em trechos nas margens do rio Sobrado, caracterizando a prática da pecuária como fator de impacto neste curso d'água (Figura 3).

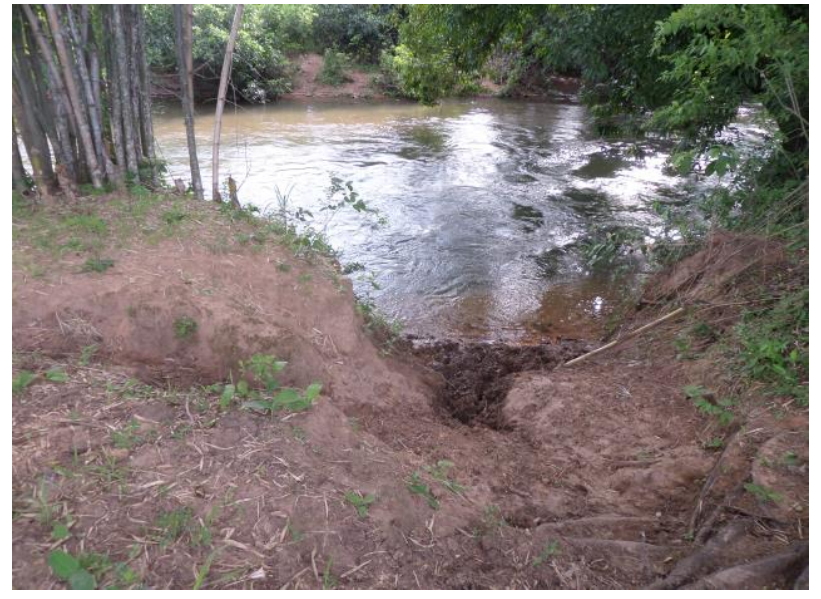

Figura 3 - Pisoteio de gado nas margens do rio Sobrado.

Segundo Ferreira (2011), a supressão da vegetação é o impacto que mais se destaca em decorrência das atividades agropecuárias, onde há a perda da vegetação nativa, a qual afeta a dinâmica das paisagens cársticas. Outro problema advindo dessa atividade é o aumento dos processos erosivos, que ocorrem de forma mais intensa principalmente pelo fato do solo estar exposto. A qualidade da água é afetada, pois a ausência da vegetação irá alterar sua composição, além de dificultar sua infiltração, comprometendo a interação da água com o substrato húmico e as raízes. Os aquíferos cársticos são contaminados pelo uso descontrolado de pesticidas, sendo esta água utilizada para abastecimento de populações humanas (FERREIRA, 2011).

Piló (1999) afirma que, a ausência de sistemas de drenagem, a baixa precipitação pluviométrica e a alta evapotranspiração, induzidos pela retirada da vegetação podem gerar como consequência a salinização dos 
solos. Gillieson (1996) ainda complementa que a substituição da cobertura vegetal compromete as cavernas que estão abaixo das lavouras, devido a alteração das condições hidrológicas.

Ford e Williams (2007) destacam entre os impactos humanos, a poluição das águas. Nas paisagens cársticas os sistemas hidrológicos são os mais afetados por essas ações, isso ocorre pela presença de águas superficiais e pelas dificuldades ligadas à rede de condutos subterrâneos associados aos frágeis ecossistemas.

Com a análise in loco, foram observadas várias propriedades rurais, com predomínio de pecuária e agricultura de subsistência, com destaque para queimadas e desmatamentos como principais impactos ambientais observados em campo. Muitos locais às margens do rio Sobrado estão em contato com atividades irregulares de recreação, onde pessoas deixam lixo e restos de fogueira, comprometendo o leito, o curso do rio e a vegetação (Figura 4).

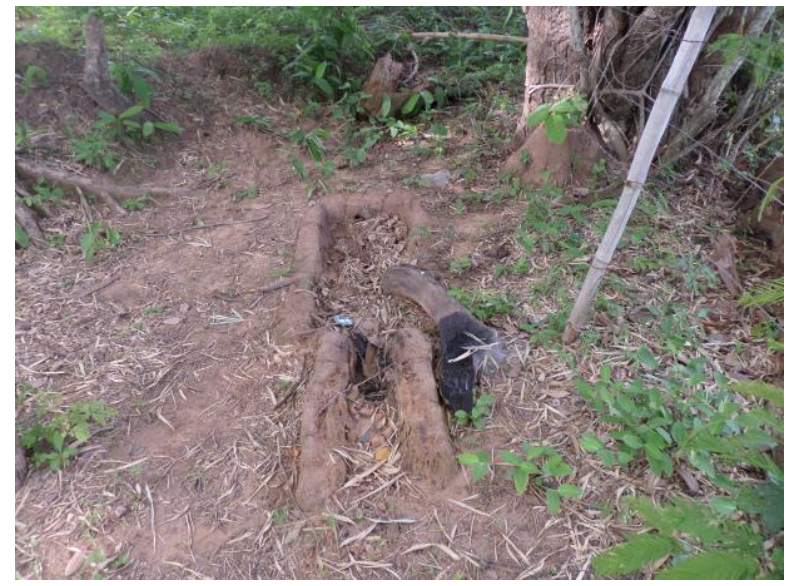

Figura 4 - Restos de fogueira nas margens do rio Sobrado.

Nas proriedades rurais nota-se a presença de processos erosivos em níveis de ravinamento pela ação de escoamentos superficiais até desbarrancamentos, principalmente nas extremidades das estradas, além da fixação de cercas, onde a vegetação é retirada deixando o solo desprotegido. Sulcos são facilmente vistos por consequência da adição de pelitos para a pavimentação de estradas (Figura 5). Canais são soterrados para a introdução de manilhas para a passagem de água (Figura 6). Como resultado, há a ocorrência de afloramentos influenciados pelos processos erosivos deixando o carste exposto. 


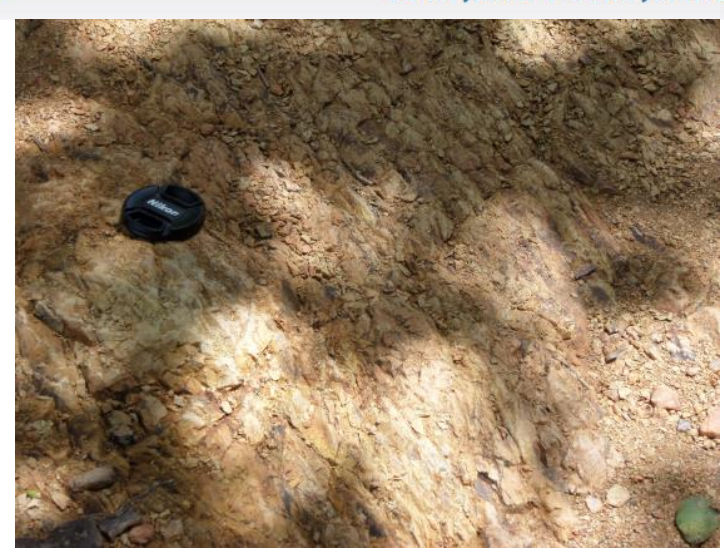

Figura 5 - Presença de pelitos na pavimentação de estradas.

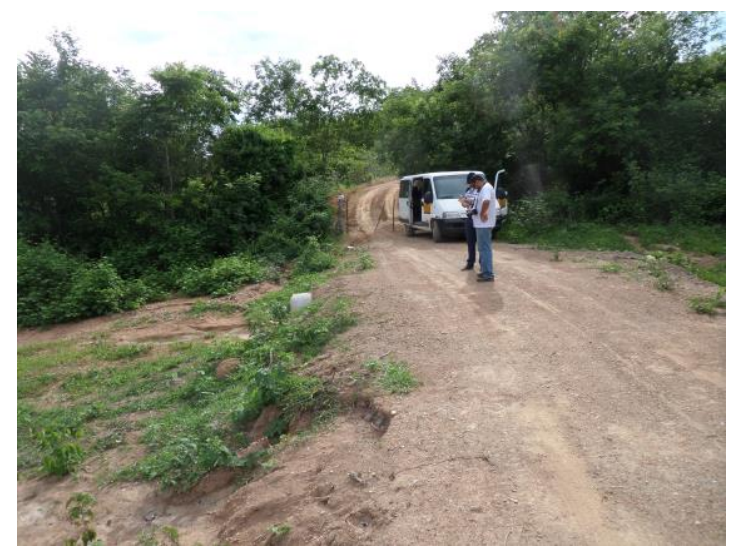

Figura 6 - Presença de manilhas para a passagem de água.

Como mostra o mapa, o bioma predominante é o Cerrado, classificado principalmente em Campo Rupestre e Cerrado Sentido Restrito, no entanto, essa vegetação é suprimida quase completamente para a introdução de pastagem. Em outras localidades é possível perceber a inexistência de homogeneidade na paisagem vegetal, devido a inserção de cultura de subsistência e construção de torres de comunicação.

Afloramentos rochosos são nitidamente visíveis por meio do mapa, e através de observações mais detalhadas de campo, foram notadas feições cársticas como: dolinas, uvalas, sumidouros e maciços rochosos, nos quais se encontram vulneráveis às ações antrópicas. A maioria das dolinas observadas, foram reaproveitadas para o represamento de água, foi retirada a cobertura vegetal e construídas estradas em suas margens. Não apenas nas dolinas, mas nas uvalas e sumidouros há a presença de pastagens em suas proximidades.

Os terrenos cársticos podem apresentar maior ou menor fragilidade de acordo com o tipo de atividade atuante, dessa forma Floriani (2003) destaca a ocupação urbana e o uso agrícola. Com relação as feições 
XVII Simpósio Brasileiro

de Geografia Fisica Aplicada

I Congresso Nacional

de Geografia Física
OS DESAFIOS DA GEOGRAFIA FÍSICA NA FRONTEIRA DO CONHECIMENTO

Instituto de Geociências - Unicamp

Campinas - SP

28 de Junho à 02 de Julho de 2017

cársticas, ainda afirma sobre os riscos de afundamentos em locais com a presença de dolinas, comprometendo atividades como escavações e construções. Por serem feições com áreas de recarga e descarga dos aquíferos, os sumidouros possuem sua drenagem muito vulnerável a qualquer tipo de poluente.

No rio Azuis, além da atividade turística, é possível perceber residências, estabelecimentos comerciais e a prática de agricultura de subsistência em sua planície de inundação (Figura 7). Outros problemas como a captação de água, acúmulo de lixo, restos de fogueira, pavimentação inadequada, que se encontra instável devido ao depósito de talos, e desmatamentos, são atividades que exigem infraestrutura e constante fiscalização, mas que no entanto, não são feitas. Não apresentam gestão adequada o suficiente para suprir as exigências ambientais e turísticas.

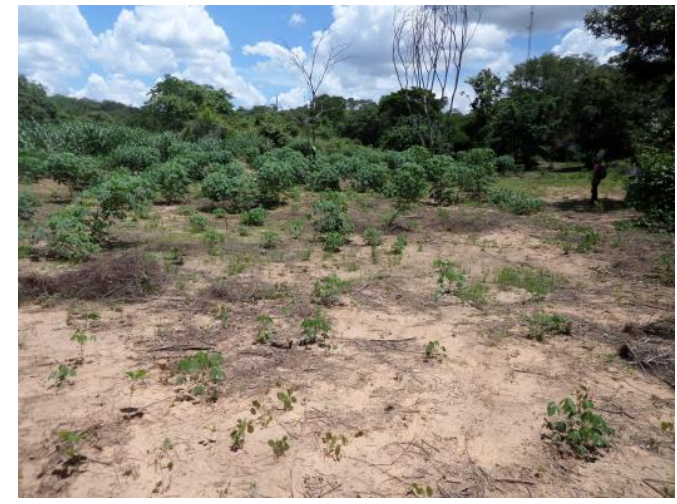

Figura 7 - Agricultura de subsistência na planície de inundação do rio Azuis.

Foi observado no rio Azuis placas de orientação para os turistas, porém não são respeitadas pelos mesmos. Alguns proprietários dos estabelecimentos comerciais investem minimamente em infraestrutura para atender ao turismo, mas o que se percebe são práticas que não trarão resultados satisfatórios aos cuidados ambientais como, introdução de grama e delimitação da área por meio de telas e cercas.

Por ser uma feição cárstica caracterizada como surgência, o rio Azuis apresenta águas cristalinas que atraem turistas não apenas por possuir atributos cênicos, mas por despertar a curiosidade dos mesmos. Muitos deles não tem conhecimento sobre os processos de formação e dinâmica do carste, isso reflete em sérias consequências, pois as pessoas sem o mínimo cuidado, entram em contato com a surgência, além de criarem barramentos para aumentar o volume do rio, comprometendo toda sua dinâmica (Figura 8). 

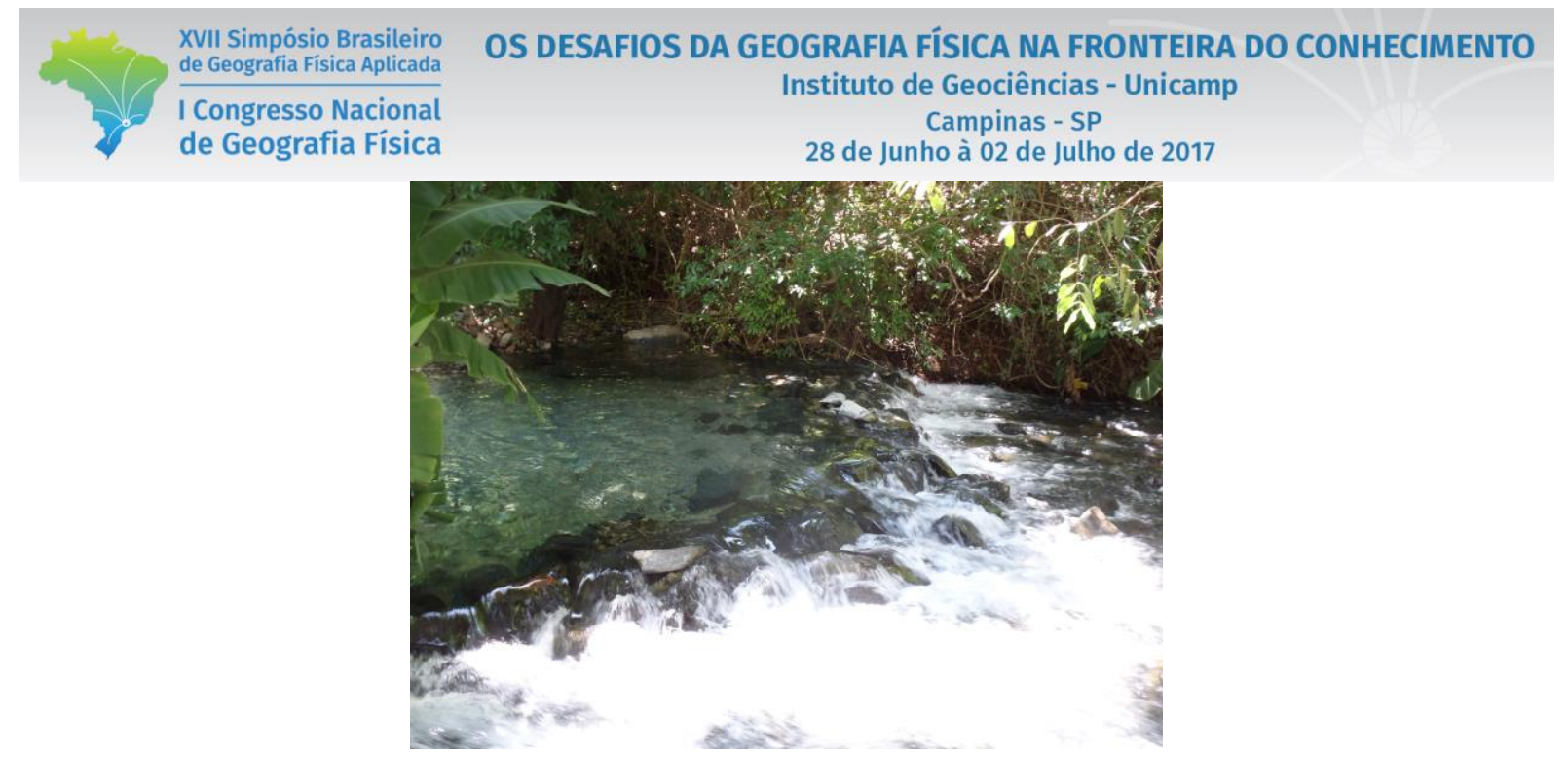

Figura 8 - Aumento do volume de água por meio de barramentos no rio Azuis.

Existem infraestruturas que dão acesso as partes inferiores do rio Azuis, no entanto, nota-se as consequências que comprometem o carste, as questões ambientais e a segurança das pessoas que frequentam o local, como por exemplo a presença de fios elétricos bem próximos ao curso d'água onde estão os turistas (Figura 9). Essa área apresenta um grau de fragilidade muito elevado e está vulnerável a vários distúrbios por ser uma feição cárstica.

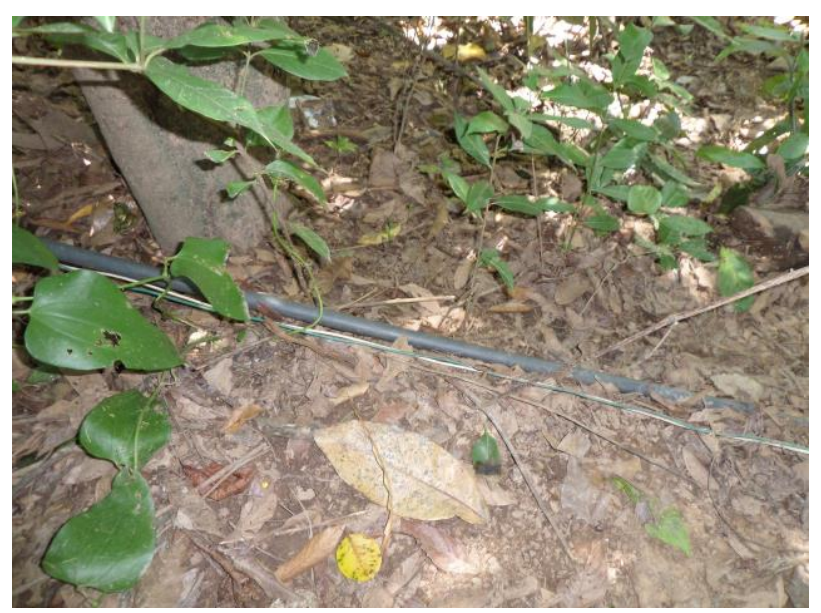

Figura 9 - Fios elétricos expostos próximos ao rio Azuis.

Até o momento da realização do trabalho de campo, não havia mudanças significativas referentes aos cuidados ambientais do local, isso demonstra o pouco interesse dos moradores, donos de estabelecimentos e principalmente dos órgãos responsáveis. 


\section{Considerações Finais}

O presente estudo buscou tecer algumas considerações no entorno do rio Azuis com relação a análise do uso e ocupação do solo, com reflexo na alteração da paisagem, tendo em vista ser parte de um trabalho mais abrangente, que visa a caracterização da paisagem cárstica em seu entorno.

A metodologia proporcionou um melhor conhecimento da área estudada, além de contribuir na confecção do mapa de uso e ocupação da terra. Observações de campo serviram não somente para a atualização das informações referentes ao local, como também reflexões sobre como a paisagem está sendo afetada pelas atividades antrópicas.

A área apresenta inúmeras possibilidades de estudos do carste, por estar situada em uma porção onde se encontra a maior incidência de rochas carbonáticas no sudeste do Tocantins, porém necessita de cuidados voltados para um Plano de Manejo adequado com o objetivo de evitar sérias pertubações ambientais.

No tocante ao uso da terra, é necessária uma participação assídua do poder público no que diz respeito a fiscalização e preservação, fato que não pôde ser visto em campo. Não apenas por ser uma área turística, mas também por apresentar relevância atribuída ao carste, muito deve ser feito referente as questões ambientais, como: orientação aos comerciantes e visitantes, ações que envolvam a mobilização da comunidade (escolas, secretarias, entre outros) e investimento em infraestrutura adequada.

Por mais que seja uma área que apresente várias potencialidades, primeiramente deve partir do interesse da população que reside e trabalha em suas proximidades, garantir o seu cuidado e preservação. Deve ser explorada com todos os cuidados possíveis, apoiando-se principalmente na legislação ambiental com constante fiscalização. Dessa forma, faz se necessário o trabalho em conjunto com o poder público e a comunidade.

\section{Referências Bibliográficas}

BRASIL - Ministério das Minas e Energia. Secretaria Geral (1982) - Projeto RADAMBRASIL. Folha SD 23 Brasília; geologia, geomorfologia, pedologia, vegetação e uso potencial da terra. Rio de Janeiro, 660 p.

CAVALCANTI, Lucas Costa de Souza. Cartografia de paisagens: fundamentos. São Paulo: Oficina de Textos, 2014.

CAMPOS, J. E. G; DARDENE, M. A. (1997) - Estratigrafia e sedimentação da Bacia Sanfranciscana: Uma revisão. Revista Brasileira de Geociências, 27, p. 269-282. 


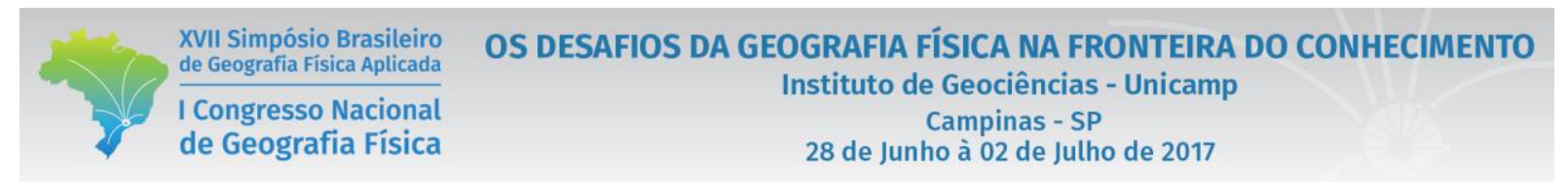

FERREIRA, C. F. Análise de impactos ambientais em terrenos cársticos e cavernas. In: Instituto Chico Mendes de Conservação da Biodiversidade. Curso de Espeleologia e licenciamento ambiental. Brasília, 2011.

FLORIANI, Nicolas. Avaliação da fragilidade geossistêmica de uma microbacia sobre geologia cárstica: Potencial e limitações. 2003. 147 f. Dissertação (Mestrado) - Curso de Pós-graduação em Agronomia, Departamento de Área de Concentração Ciências do Solo do Setor de Ciências Agrárias, Universidade Federal do Paraná, Curitiba, 2003.

FORD, Derek; WILLIAMS, Paul. Karst Hydrogeology and Geomorphology. [Rev. ed.] United Kingdom: Wiley, 2007.

GILLIESON, D. Caves: processes, development, management. Oxford: Clackwell Publishers, 1996.

GOMES, Mauro. Proposta metodológica para identificação de áreas vulneráveis para a conservação do patrimônio espeleológico brasileiro. 2010. 62 f. Monografia

IGLESIAS, Mario; UHLEIN, Alexandre. Estratigrafia do Grupo Bambuí e coberturas fanerozóicas no vale do rio São Francisco, norte de Minas Gerais. Revista Brasileira de Geociências, v. 39, n. 2, p. 256-266, 2009.

HARDT, Rubens. Sistema cárstico e impactos antrópicos: considerações sobre manejo. In: Simpósio de PósGraduação em Geografia do Estado de São Paulo SIMPGEO-SP., 2008, São Paulo. VIII Seminário de PósGraduação em Geografia da Unesp - Rio Claro, 2008, p. 1295 - 1309.

INVTUR - Inventário Turístico. Inventário da Oferta Turística de Aurora - Tocantins, 24 p., 2008.

KARMANN, Ivo; SÁNCHEZ, Luís Enrique. Distribuição das rochas carbonáticas e províncias espeleológicas do Brasil. Espeleo-Tema, v. 13, p. 105-167, 1979.

MORAIS, Fernando de. Caracterização Geomorfológica da Região de Aurora do Tocantins, Brasil. Revista Brasileira de Geomorfologia, v. 14, n. 2, p.163-170 (Abr. - Jun.) 2013.

MORAIS, Fernando de. Aspectos gerais da área cárstica de Aurora do Tocantins. Para conhecer a Terra memórias e notícias de geociências no espaço lusófono. Imprensa da Universidade de Coimbra. Coimbra, p. 1-12, 2012. Disponível em: <http://hdl.handle.net/10316.2/31489>. Acesso em: 08 jun. 2016.

NOVO, E. M. L. M. Sensoriamento Remoto: princípios e aplicações. São Paulo: Edgard Blucher, 2010. 388p.

SILVA, Fabiane Fernandes da. Gestão de áreas cársticas em Aurora do Tocantins e Dianópolis - TO: uma análise a partir de perturbações ambientais. 2012. 131 f. Dissertação (Mestrado em Ciências do Ambiente) Universidade Federal do Tocantins, Palmas, 2012.

PILÓ, Luís Beethoven; AULER, Augusto. Introdução à espeleologia. In: ICMBio/CECAV. (Org.). III curso de espeleologia e licenciamento ambiental. Brasília/DF: Adaequatio estúdio de criação, 2011. Cap. 1. p. 7-23. 
PILÓ, Luís Beethoven; AULER, Augusto. Ambientes cársticos de Minas Gerais: Valor, fragilidade e impactos ambientais decorrentes da atividade humana. O Carste. Belo Horizonte, vol.11, n.3, p.50-58 (Jul.) 1999.

SILVA, Fabiane Fernandes da; MORAIS, Fernando de. Análise multitemporal da cobertura vegetal no entorno de dez cavernas em Aurora do Tocantins - TO. In: Congresso Brasileiro de Espeleologia, 31, 2011, Ponta Grossa-PR. Anais... Ponta Grossa-PR, 2011, p. 19 - 24.

SEPLAN (SECRETARIA DO PLANEJAMENTO E MEIO AMBIENTE) (2008) - Atlas do Tocantins: subsídios ao planejamento da gestão territorial. Diretoria de Zoneamento Ecológico-Econômico - DZE. 4 ed. Palmas, 49 p.

TRAVASSOS, Luiz Eduardo Panisset; Varela, Isabela Dalle. Aspectos legais do uso da água em regiões cársticas. Ciência \& Tecnologia, v. 8, p. 386-400, 2008.

VALERIANO, Márcio de Morisson. Modelo digital de variáveis morfométricas com dados SRTM para o território nacional: o projeto TOPODATA. In: XII Simpósio Brasileiro de Sensoriamento Remoto, v. 12, p. 3595 $3602,2005$. 